\title{
OPTIMALISASI PERAN ORANGTUA MELALUI EDUKASI PARENTAL EMOTIONAL COACHING DALAM UPAYA MENINGKATKAN KETERAMPILAN MERESPON EMOSI NEGATIF ANAK TUNARUNGU DI SLB X KECAMATAN KARANGPILANG
}

\author{
Starry Kireida Kusnadi \\ Universitas Wijaya Putra \\ starrykusnadi@uwp.ac.id
}

\begin{abstract}
Abstrak
Tunarungu adalah seseorang yang mengalami gangguan pendengaran yang meliputi seluruh gradasi ringan, sedang, dan sangat berat yang menyebabkan terganggunya proses perolehan informasi atau bahasa sebagai alat komunikasi. Gangguan pendengaran (tunarungu) seringkali menimbulkan masalah tersendiri. Masalah utama pada anak tunarungu tidak hanya aspek itu saja yang terpengaruh, melainkan seluruh aspek perkembangannya dan aspek kehidupannya juga terpengaruh. Penderitaan anak tunarungu berpangkal dari kesulitannya mendengar, sehingga pembentukan bahasa sebagai salah satu cara komunikasi menjadi terhambat. Dengan ketidakmampuan berbahasa khususnya secara verbal, anak akan mengalami kesulitan dalam menyampaikan pikiran, perasaan, gagasan, kebutuhan dan kehendaknya pada orang lain, sehingga kebutuhan mereka tidak terpuaskan secara sempurna. Disamping tidak dimengerti oleh orang lain, anak tunarungu juga sulit memahami orang lain, sehingga tidak jarang mereka merasa terkucil atau terisolasi dari lingkungan sosialnya. Respon orangtua terhadap momen emosional anak memengaruhi pemahaman anak mengenai emosi, misalnya mengenai bagaimana cara mengekspresikan suatu emosi atau bagaimana cara meregulasi emosi. Tujuan pengabdian ini adalah untuk meningkatkan keterampilan orangtua dalam merespon emosi negatif anak tunarungu menggunakan emotional coaching. Metode pelaksanaan yang digunakan adalah memberikan edukasi tentang parental emotional coaching kepada orangtua yang memiliki anak tunarungu. Diharapkan dengan adanya kegiatan ini para orangtua dapat lebih terampil dalam merespon emosi negatif anak sehingga orangtua dapat memberikan respon yang tepat dan menjadi pelatih emosi yang baik bagi anak.
\end{abstract}

Kata Kunci : Parental Emotional Coaching, Keterampilan, Emosi Negatif, Tunarungu

\section{PENDAHULUAN}

Anak yang dilahirkan secara sehat baik dalam hal fisik dan psikis merupakan harapan bagi semua orangtua yang sudah menantikan kehadiran anak dalam kehidupan perkawinan mereka. Anak yang lahir sebagai anggota baru dalam keluarga membawa harapan baru bagi kedua orangtua. Namun terkadang kenyataan tidak sesuai dengan harapan orangtua. Anak bisa mengalami berbagai macam kekurangan atau keterbatasan fisik dan psikis pada saat dilahirkan yang tidak bisa ditentukan oleh manusia. Orang awam sering menyebutnya sebagai anak cacat. Istilah lain darinya adalah anak berkebutuhan khusus. Anakanak berkebutuhan khusus ini bisa mengalami salah satu gangguan atau ketunaan dan bisa juga mengalami beberapa gangguan (tunaganda). Menurut Manggungsong (2009) bahwa gangguan atau ketunaan yang biasanya dialami anak sebagai berikut gangguan fisik (tunadaksa), emosional dan perilaku, kesulitan belajar (tunalaras), mental 
retardasi (tunagrahita), gangguan penglihatan (tunanetra) dan gangguan pendengaran (tunarungu). Gangguan pendengaran (hearing impairment) atau di Indonesia dikenal dengan istilah tunarungu atau tuli merupakan salah satu gangguan pada alat indera yaitu telinga. Menurut data Kementerian Sosial pada tahun 2006 (data pusdatin) mencatat bahwa terdapat 295.763 anak dengan kecacatan. Jenis kecacatan yang banyak terjadi adalah tunadaksa $(35,8 \%)$; tunanetra $(17 \%)$; tunarungu $(14,27 \%)$; tunagrahita $(12,15 \%)$ dan lain lain (kurang dari 7\%) (dalam Kementerian Kesehatan Republik Indonesia, 2010).

Menurut Mores (dalam Mangunsong, 2009) ketunarunguaan adalah suatu kondisi dimana individu tidak mampu mendengar dan hal ini tampak dalam wicara atau bunyi-bunyian lain baik dalam derajat frekuensi ataupun intensitas. Definisi yang kuantitatif secara khusus menunjuk pada gangguan pendengaran sesuai dengan hilangnya pendengaran yang dapat diukur dengan alat audiometri. Audiometri merupakan alat yang dapat mengukur seberapa jauh seseorang dapat mendengar atau seberapa besar hilang pendengaran dan ditunjukkan dalam satuan desibel (Db).

Mangunsong (2009) menyatakan bahwa anak dengan gangguan pendengaran (tunarungu) seringkali menimbulkan masalah tersendiri. Masalah utama pada anak dengan gangguan aspek itu saja yang terpengaruh, melainkan seluruh aspek perkembangannya dan aspek kehidupannya juga terpengaruh. Penderitaan anak tunarungu berpangkal dari kesulitannya mendengar, sehingga pembentukan bahasa sebagai salah satu cara komunikasi menjadi terhambat. Dengan ketidakmampuan berbahasa, khususnya secara verbal, anak akan mengalami kesulitan dalam menyampaikan pikiran, perasaan, gagasan, kebutuhan dan kehendaknya pada orang lain, sehingga kebutuhan mereka tidak terpuaskan secara sempurna. Disamping tidak dimengerti oleh orang lain, anak tunarungu juga sulit memahami orang lain, sehingga tidak jarang mereka merasa terkucil atau terisolasi dari lingkungan sosialnya.

Heward (1998) menyatakan bahwa fungsi pendengaran merupakan sesuatu hal yang sangat penting bagi anak di tahun pertama kehidupan mereka untuk menerima dan mempelajari informasi.
Pendengaran merupakan hal yang penting untuk setiap aspek dari kehidupan sehari-hari kita. Jika tidak mendengar, akan menjadi sulit untuk berpartisipasi secara penuh dalam aktivitas di sekolah, pekerjaan, tetangga, teman, bahkan dengan keluarga sendiri. Selain itu juga, gangguan pendengaran bisa juga mempengaruhi perilaku dan perkembangan sosial emosional anak. Penelitian yang tersedia tidak begitu jelas mengambarkan pengaruh dari kehilangan pendengaran terhadap perilaku. Namun hal ini muncul bahwa anak yang tunarungu akan sukses berinteraksi dengan anggota keluarga, teman, dan orang-orang dalam komunitas bergantung pada perilaku orang lain dan kemampuan anak dalam berkomunikasi secara timbal balik dengan cara yang bisa diterima.

Goldstein (2005) menyatakan bahwa emosi merupakan pengalaman subjektif. Namun, tentu saja anak-anak yang memiliki gangguan pendengaran digambarkan bahwa mereka lebih sering memakai emosi negatif dibandingkan anakanak lainnya. Emosi negatif yang ada pada anak tunarungu baik yang kategori severe, profound, atau mild adalah rasa marah yang menunjukan tandatanda seperti frustasi, keras kepala dan bisa juga menjadi menarik diri.

Menurut Roternberg \& Eisenberg (dalam Papalia, 2008) kontrol terhadap emosi negatif merupakan salah satu aspek pertumbuhan emosional. Anak-anak belajar tentang apa-apa yang membuat mereka marah, takut, sedih, dan bagaimana orang lain bereaksi dalam menunjukan emosi ini, dan mereka belajar mengadaptasikan perilaku mereka dengan emosi-emosi tersebut. Mereka juga belajar perbedaan antar emosi dan mengekspresikannya.

Hurlock (1993) mengatakan bahwa ada 5 jenis emosi pada anak, diantaranya adalah : a) Marah. Penyebab amarah yang paling umum adalah pertengkaran mengenai permainan, tidak tercapainya keinginan dan serangan yang hebat dari anak lain. Anak mengungkapkan rasa marah dengan ledakan amarah yang ditandai dengan menangis, berteriak, menggertak, menendang, melompat atau memukul orang lain. b) Takut. Kebiasaan atau ingatan tentang pengalaman yang kurang menyenangkan berperan penting dalam menimbulkan rasa takut, seperti cerita-cerita, gambar- gambar, acara televisi, radio maupun film yang mengandung unsur yang menakutkan.

$$
\text { Pendidikan }
$$

903 
Biasanya reaksi awal anak untuk rasa takut adalah panik, kemudian menjadi lebih khusus seperti lari, menghindar, bersembunyi, menangis dan menghindari situasi yang menakutkan. c) Cemburu. Anak menjadi cemburu apabila ia menginar bahwa minat dan perhatian orangtuanya beralih kepada orang lain di dalam keluarga. Biasanya kehadiran adik yang baru lahir. Anak yang lebih muda dapat mengungkapkan kecemburuannya secara terbuka atau menunjukkannya dengan kembali berperilaku seperti anak kecil, seperti mengompol, pura-pura sakit atau menjadi nakal. Perilaku ini semua bertujuan untuk menarik perhatian. d) Gembira atau senang. Anak merasa gembira biasanya dikarenakan mendapatkan nilai yang bagus, hadiah, dan pujian. Anak mengungkapkan kegembiraanya dengan tersenyum dan tertawa, melompat-lompat atau memeluk benda atau orang yang dapat membuatnya bahagia. e) Sedih. Anak - anak merasa sedih karena kehilangan segala sesuatu yang dicintainya atai sesuatu yang dianggap penting bagi dirinya apakah itu orang, binatang atau benda mati seperti mainan. Secara khas anak mengungkapkan kesedihannya dengan menangis dan dengan kehilangan minat terhadap kegiatan normalnya termasuk makan.

Bryant (1987) menyatakan pada pertengahan masa kanak-kanak, anak-anak menyadari dengan baik aturan penampilan emosional kultur mereka. Emosional kultur semacam ini dikomunikasikan melalui reaksi orangtua terhadap penunjukan ekspresi oleh anak. Orangtua yang mengakui dan melegitimasi perasaan tertekan anak mendorong perkembangan empati dan prososial. Sementara itu menurut pendapat Fabes, Leornard, Kupenoff, \& Martin (2001) ketika orangtua menunjukan ketidaksetujuan, atau menghukum, emosi negatif, emosi tersebut bisa jadi semakin intens ditunjukkan dan dapat merusak penyesuaian sosial anak. Atau anak tersebut mungkin belajar untuk menyembunyikan emosi negatif tetapi bisa menjadi cemas dalam situasi yang membangkitkan emosi tersebut (dalam Papilia, 2008).

Gross (2007) juga menyatakan bahwa pemahaman anak dalam mengembangkan regulasi emosi dipengaruhi oleh input dari pengasuh atau orangtua. Orangtua yang menunjukkan dukungan ketika anak mengalami emosi negatif, mengajarkannya untuk mengatasi perasaan tersebut, yang akan membuat anak mengembangkan pemahamannya akan pengalaman emosi dan berdampak pada regulasi diri yang efektif. Regulasi emosi bisa didukung dan diganggu oleh bagaimana orang lain mengevaluasi perasaan seseorang. Respon simpati, respon yang membangun menegaskan bahwa perasaan seseorang itu sesuai dan memberikan sumber dukungan sosial yang membantu dalam coping melalui pemahaman dan nasehat yang diberikan oleh orang lain. Tetapi penolakan, kritikan, atau respon meremehkan bisa menambah stress sebagai hambatan dari regulasi emosi.

Gottman dan kawan-kawan (dalam Cortell, 2009) menyatakan bahwa pikiran dan perasaan orangtua mengenai emosi yang mereka alami sendiri sama halnya juga dengan dunia emosi dari anak-anak mereka. Dari hal ini lah, Gottman mengidentifikasi filosofi-filosofi yang berbeda bahwa orangtua bisa memiliki pengaruh terhadap emosi-emosi anak. Mendengar pandangan para orangtua mengenai strategi-strategi yang mereka gunakan untuk membantu anak mengatur emosi membuat Dr. Gottman mengindentifikasi "emotion coaching".

Parental emotional coaching merupakan suatu proses dimana orangtua dengan aktif mendengarkan ungkapan perasaan anaknya, menerima perasaan anaknya serta memberikan bimbingan, batasan perilaku, dan membantu anak menyelesaikan permasalahannya agar anak dapat belajar bagaimana mengendalikan perasaan atau emosi yang dirasakannya dengan cara yang benar.

Gottman dan DeClaire

(1997)

mengemukakan lima langkah dalam parental emotional coaching yang umumnya digunakan oleh orangtua untuk meningkatkan kepekaan orangtua menghadapi emosi negatif anak yaitu (1) Menyadari emosi diri sendiri dan emosi anak (awareness), (2) Menerima emosi anak sebagai peluang untuk lebih dekat dengan mereka dan mengajarkan kepada mereka bagaimana cara mengatasi emosi mereka (acceptance), (3) Mendengarkan dengan empati dan pengertian (empathy), (4) Membantu anak memberi label pada emosi yang sedang dirasakannya dengan kata-kata (labeling), dan (5) Menentukan batas-batas perilaku yang boleh dilakukan anak ketika membantu anak menyelesaikan masalahnya (problem-solving).

$$
\text { Pendidikan }
$$




\section{METODE}

Metode pelaksanaan yang digunakan adalah memberikan edukasi tentang langkah-langkah untuk mengaplikasikan parental emotional coaching kepada orangtua yang memiliki anak tunarungu.

Langkah pertama yang dilakukan adalah who am $i$. Dalam sesi 1) orangtua diminta untuk memperkenalkan diri; 2) orangtua diminta untuk menceritakan pengalamannya memiliki anak tunarungu; 3) orangtua diminta untuk menceritakan emosi negatif yang ditunjukkan oleh anak.

Kedua, parental emotional coaching. Dalam sesi ini 1) peneliti memberikan penjelasan tentang pengertian parental emotional coaching. 2) peneliti menjelaskan lima langkah yang digunakan orangtua dalam menjadi pelatih emosi (emotion coaching) yang baik, diantaranya: awareness; acceptance; emphaty; labeling; dan problem solving. 3) peneliti menjelaskan tentang awareness, awareness merupakan proses menyadari emosi diri sendiri dan emosi anak. Peneliti memberikan pemahaman tentang bagaimana orangtua dapat menyadari emosi yang dimiliki, serta dapat menyadari emosi yang dimiliki oleh anak-anak. Peneliti memberikan contoh kasus, dan memutarkan video pendek tentang awareness. 4) acceptance, acceptance adalah bagaimana orangtua menerima emosi anak sebagai peluang untuk lebih dekat dengan anak dan mengajarkan kepada anak bagaimana cara mengatasi emosi. Dengan memberikan contoh kasus, dan memutarkan video pendek tentang acceptance. 5) emphaty, emphaty adalah mendengarkan dengan empati dan pengertian. Peneliti memberikan contoh kasus dan memutarkan video pendek tentang emphaty. 6) labeling, labeling adalah orangtua membantu anak untuk memberikan label pada emosi yang sedang dirasakannya dengan kata-kata. Peneliti memberikan contoh kasus dan memutarkan video pendek tentang labeling. 7) problem solving, problem solving merupakan proses untuk menentukan batas-batas perilaku yang boleh dilakukan orangtua ketika membantu anak menyelesaikan masalahnya.
Ketiga, review. Dalam sesi ini peneliti menjelaskan dan memberikan kesimpulan atas langkah-langkah parental emotional coaching agar orangtua dapat menjadi perespon yang baik bagi emosi negatif anak.

\section{HASIL DAN PEMBAHASAN}

Hasil penelitian menunjukkan adanya peningkatan keterampilan orangtua mengenai cara merespon emosi negatif anak tunarungu dengan menggunakan metode parental emotional coaching.

Hasil penelitian ini sejalan dengan penelitian sebelumnya yang dilakukan oleh Sarry \& Ervika (2018) menyebutkan bahwa parental emotional coaching efektif bagi orangtua untuk meningkatkan kemampuan menghadapi emosi negatif anak tunarungu.

Hasil penelitian Intan, Kurniawati \& Handayani (2017) yang menyebutkan bahwa pelatihan emotional coaching efektif untuk meningkatkan pengetahuan dan keterampilan orangtua dalam merespon momen emosional anak usia 4-5 tahun.

Hasil penelitian Pratiwi, Sofia, \& Anggraini (2018) menyebutkan aspek melatih emosi atau emotion coaching berhubungan positif signifikan terhadap regulasi emosi anak yang berarti bahwa, semakin banyak orangtua melakukan pelatihan emosi, maka kemampuan regulasi emosi anak juga akan semakin meningkat.

Hasil penelitian Wilson, Petaja, Yun, King, Berg, Kremmel, and Cook (2014) menyebutkan intervensi yang berfokus pada pembinaan emosi orangtua dapat terbukti bermanfaat untuk meningkatkan keterampilan pengaturan diri dan perhatian anak-anak dengan masalah sosial dan perilaku.

Berdasarkan hasil penelitian dapat dijelaskan bahwa orangtua lebih memiliki pemahaman terhadap emotion coaching. Orangtua belajar aktif mendengarkan ungkapan perasaan anak, menerima perasaan anak serta memberikan bimbingan, batasan perilaku, dan membantu anak menyelesaikan permasalahannya agar anak dapat belajar bagaimana mengendalikan perasaan atau emosi yang dirasakannya dengan cara yang benar.

Selain itu Gottman, Katz, dan Hooven (1997, dalam Alegre, 2011) menyatakan bahwa

$$
\text { Pendidikan }
$$


ketika orangtua menerima emosi yang ditampilkan anak dan membantu anak untuk memahami dan menggunakan informasi dari emosi tersebut untuk berperilaku dengan cara yang tidak positif dan efisien, orangtua yang telah mengikuti langkahlangkah emotional coaching akan menunjukkan kemampuan yang lebih baik dalam mengatur emosinya. Akan tetapi orangtua yang tidak pernah menggunakan langkah-langkah emotion coaching atau lebih memilih memberikan hukuman, mengabaikan dan memberikan reaksi yang tidak tepat terhadap emosi negatif yang ditampilkan anak, maka akan berhubungan dengan kemampuan anak dalam mengatur emosinya (Perlman, Camras, \& Pelphrey, 2008 dalam Alegre, 2011).

Denham dan Grout (1992, dalam Alegre, 2011) juga telah menyatakan bahwa ketika orangtua lebih ekspresif dan responsif dalam memahami emosi anak, orangtua akan mendorong anak untuk dapat lebih mampu dalam mengekspresikan emosi yang dimiliki dan menyampaikan proses emosional yang dirasakan anak. Anak akan memiliki kemampuan yang lebih baik dalam mengatur emosinya (Denham \& Grout, 1994; Denham, Mitchell-Copeland, Strandberg, Auerbach, \& Blair, 1997, dalam Alegre, 2011).

\section{KESIMPULAN}

Berdasarkan hasil penelitian maka dapat disimpulkan bahwa edukasi parental emotional coaching yang diberikan kepada orangtua yang memiliki anak tunarungu efektif untuk meningkatkan keterampilan orangtua dalam merespon emosi negatif anak.

Berdasarkan hasil penelitian tersebut maka saran-saran praktis yang bisa diberikan kepada orangtua adalah orangtua harus menerapkan langkah-langkah dalam parental emotional coaching di kehidupan sehari-hari. Karena dengan menerapkan langkah-langkah tersebut orangtua akan lebih menyadari, menerima, berempati dan memberikan pengertian, serta membantu menyelesaikan masalah anak.

Selain itu, menimbang kesulitan komunikasi yang dimiliki anak tunarungu sehingga anak sulit mengontrol emosi yang dimilikinya dan lebih ekspresif dalam meluapkan apa yang dirasakannya oleh karena itu orangtua juga diharapkan dapat melakukan pendekatan kepada anak dan membimbingnya untuk mengontrol dan mengekspresikan emosi dengan cara yang tepat.

\section{REFERENSI}

Alegre, A. (2011). Parenting Styles and Children's Emotional Intelligence: What do We Know?. The Family Journal Counseling and Therapy for Couples and Families, 19(1) 56-62, DOI: $10.1177 / 1066480710387486$.

Bernard, H. S. (1981). Identity Formation in Late Adolescense. Dalam Santrock, J.W.1995. Life-Span Development. Perkembangan Masa Hidup. Edisi kelima. Jilid 2. Jakarta: Erlangga.

Bryant, Corallie, Louis G.White 1987. Manajemen Pembangunan Untuk Negara Berkembang. Jakarta: LP3S.

Cortell, R. (2009). A pilot study of emotional coaching and mindfulness program for parents of early Adolescents (Published doctoral dissertation) Chatolic University of America, USA.

Denham, S. A., \& Grout, L. (1992). Mothers' emotional expressive-ness and coping: Relations with preschoolers' socialemotional competence. Genetic, Social, and General Psychology Monographs,118, 73-101. Diakses dari https://www.researchgate.net

Denham, S. A., Mitchell-Copeland, J., Strandberg, K., Auerbach, S., \&Blair, K. (1997). Parental contributions to preschoolers' emotiona competence: Direct and indirect effects. Motivation and Emotion, 21, 65-86. Diakses dari https://www.researchgate.net

Enright. R. D. (1980). Parental Influence on The Development of Adolescence Autonomy and Identity. Dalam Santrock, J.W. 1995. Life-Span Development. Perkembangan Masa Hidup. Edisi kelima. Jilid 2. Jakarta: Erlangga. 
Goldstein, Dan. (2005). The Hearing Impaired Child. London dan New York : RoutledgeFalmer.

Gottman, J., Declaire, J., \& Goleman, D. (1998). Raising an emotionally intelligent children the heart of parenting. New York, Simon \& Schuster Paperback.

Gottman, J. M., Katz, L.F., \& Hooven, C. (1997). Meta-emotion. How families communicate emotionally. Mahwah, NJ: Lawrence Erlbaum. Diakses dari https://www.researchgate.net

Gottman, J. M., Katz, L.F., \& Hooven, C. (1997). Meta-emotion. How families communicate emotionally. Mahwah, NJ: Lawrence Erlbaum.

Gus, L., Rose, J., \& Gilbert, L. (2015). Emotion Coaching: A universal strategy for supporting and promoting sustainable emotional and behavioural well-being. Educational \& Child Psychology Vol. 32 No. 1. The British Psychological Society, $2015 . \quad$ Diakses dari https://www.bathspa.ac.uk

Gross, J. J., \& Thompson, R. A. (2007). Emotion Regulation: Conceptual Foundations. In J. J. Gross (Ed.), Handbook of emotion regulation (pp. 3-24). New York, NY, US: The Guilford Press.

Hauser, S. T., \& Bowlds, M.K. (1990). Stress, coping and adaptation. In S.S. Feldman, G.R. Elliots (Eds.). At the Thershold: The Developing Adolescent (pp. 388-413). Cambridge, MA: Harvard University Press.

Hurlock, E. B. (1980). Psikologi Perkembangan, Suatu Perkembangan Sepanjang Rentang Kehidupan (edisi III). Jakarta : Erlangga.

Hurlock, E. B. (1993). Perkembangan Anak . Jakarta : Erlangga

Hurlock, E. B. 2000. Psikologi Perkembangan. Jakarta : Erlangga.

Heward, W. L. (1995). Exceptional Children: An Introduction to Special Education. USA: Prentice Hall.

Intan, Reno., Kurniawati, Farida., \& Handayani, Eko. (2017). Pelatihan Emotion Coaching Untuk Meningkatkan Pengetahuan dan Keterampilan Orang tua Dalam Merespon Momen Emosional
Anak Usia 4-5 Tahun. Jurnal

Psikogenesis, Vol 5 No 2, Desember

$2017 . \quad$ Diakses dari http://academicjournal.yarsi.ac.id/index.p hp/Jurnal-Online

Psikogenesis/article/view/507/349.

Kementerian Kesehatan Indonesia, 2010, Kementerian Sosial Tahun 2006, Jakarta : Kementerian Kesehatan RI.

Marcia, J. E. 1980. Ego Identity Development. Dalam Santrock, J.W.1995. Life-Span Development. Perkembangan Masa Hidup. Edisi kelima. Jilid 2. Jakarta: Erlangga.

Manggungsong, F. (2009) Pendidikan Anak Luar Biasa. Jakarta: LPSP3UI.

Papalia, D. E., Old, S. W., Feldman, \& R. D. (2008). Human Development (terjemahan A. K. Anwar). Jakarta: Prenada Media Group.

Perlman, S. B., Camras, L. A., \& Pelphrey, K. A. (2008). Physiologyand functioning: Parents' vagal tone, emotion socialization, and children's emotion knowledge. Journal of Experimental ChildPsychology, 100, 308-31. Diakses dari

https://www.researchgate.net/publication.

Pratiwi, N. M., Sofia, A., \& Anggraini F. G. (2018). Pendekatan Coaching dan Dissmising Orang Tua dengan Regulasi Emosi Anak Usia 5-6 Tahun. Indonesian Journal of Early Childhood Issues, Vol 1 No 1, Februari 2018. Diakses dari http://jurnal.fkip.unila.ac.id/index.php/IJ ECI/article/view/16510.

Safaria, T. 2005.Autisme: Pemahaman Baru untuk Hidup Bermakna Bagi Orang Tua. Yogyakarta: Graha Ilmu.

Santrock, J. W. (2003). Life - Span Development: Perkembangan Masa Hidup. Jilid 2. Jakarta: Erlangga.

Sarry, M., \& Ervika E.. (2018). Parental Emotional Coaching Untuk Meningkatkan Kemampuan Menghadapi Emosi Negatif Anak Tunarungu. Jurnal Penelitian dan PPM, Vol 5 No 2, Juli 2018. Diakses dari https://www.researchgate.net/publication /327440098. 
Tridhonanto, A. (2014). Mengembangkan Pola Asuh Demokratis. Jakarta : PT. Elex Media Komputindo.

Wilson, B. J., Petaja, H., Yun, J., King, K., Berg, J., Kremmel, L., \& Cook, D.(2014). Parental Emotion Coaching: Associations With Self-Regulation in Aggressive/Rejected and Low Aggressive/Popular Children. Jurnal National Center for Biotechnology Information, U.S. National Library of Medicine, PMC4111247, June 2014. Diakses dari https://www.ncbi.nlm.nih.gov/pmc/article s/PMC4111247/. 